\title{
Study of Corrosion Behavior of X80 Steel in Clay Soil with Different Water Contents under HVDC Interference
}

\author{
Zhenchang Xu, Yanxia Du*, Runzhi Qin, Hui Zhang \\ Institute for Advanced Materials and Technology, University of Science and Technology Beijing, \\ Beijing, 10083, China \\ *E-mail: duyanxia@ustb.edu.cn
}

doi: $10.20964 / 2020.05 .24$

Received: 6 April 2019 / Accepted: 20 June 2019 / Published: 10 April 2020

\begin{abstract}
With the large-scale construction of high voltage direct current systems, high voltage direct current (HVDC) interference on long-distance pipelines has become increasingly serious. The field tests showed that the pipe-to-soil potential caused by the HVDC interference could be several hundred volts. Thus, investigating the corrosion behavior of pipelines under such large potential has become an urgent problem in the industry. In this study, the corrosion behavior of X80 steel in clay soil with different water contents at a potential of $100 \mathrm{~V}$ produced by the HVDC interference was studied by laboratory simulation experiments. The results showed that the corrosion rates of X80 steel with different soil water contents were quite different. At the soil water contents of $17 \%, 21 \%, 25.5 \%$, $30.5 \%$, and $34.5 \%$, the corrosion rates were $1.69,10.77,31.67,85.13$, and $169.49 \mu \mathrm{m} \cdot \mathrm{h}^{-1}$, respectively. At the same time, the direct current density of the samples was found to be quite different under different soil water contents. At the soil water content $<30.5 \%$, the current density reached sharply to a peak value in a short time when the high DC interference potential was applied, then it dropped rapidly to a lower steady value and maintained for a long time near the stable value, the steady value was less than one fifth of the peak value. At the soil water content $>30.5 \%$, the current density gradually increased to a peak value, and maintained near the high peak value. The changes in the soil temperature, water content, and resistivity near the samples under interference were analyzed, indicating that the rapid decrease in the current density at lower water content was because of increasing soil temperature near the sample surface, the decrease in the soil water content, and the increase in the spread resistance. The morphologies of the corrosion products at different water contents were characterized by X-ray diffraction and scanning electron microscopy. The results showed that when the water content was $17 \%$, the main corrosion product was $\alpha-\mathrm{FeOOH}$. In addition, with increasing water content, various types of $\mathrm{FeOOH}$ began to appear, and $\gamma$-FeOOH was the main product. When the water content increased to $34.5 \%$, the main product transformed to $\mathrm{Fe}_{2} \mathrm{O}_{3}$. The analyses showed that the difference in the corrosion products under different water contents was closely related to the different current density behaviors of X80 steel under HVDC interference in different soils.
\end{abstract}


Keywords: HVDC interference; soil water content; corrosion rate; corrosion products; current density

\section{$\underline{\text { FULL TEXT }}$}

(C) 2020 The Authors. Published by ESG (www.electrochemsci.org). This article is an open access article distributed under the terms and conditions of the Creative Commons Attribution license (http://creativecommons.org/licenses/by/4.0/). 